\title{
The therapeutic role of video diaries: a qualitative study involving breastfeeding mothers
}

Article

Accepted Version

Creative Commons: Attribution-Noncommercial-No Derivative Works 4.0

Taylor, A. M., van Teijlingen, E., Alexander, J. and Ryan, K. M. (2019) The therapeutic role of video diaries: a qualitative study involving breastfeeding mothers. Women and Birth, 32 (3). pp. 276-283. ISSN 1871-5192 doi:

https://doi.org/10.1016/j.wombi.2018.08.160 Available at https://centaur.reading.ac.uk/79319/

It is advisable to refer to the publisher's version if you intend to cite from the work. See Guidance on citing.

To link to this article DOI: http://dx.doi.org/10.1016/j.wombi.2018.08.160

Publisher: Elsevier

All outputs in CentAUR are protected by Intellectual Property Rights law, including copyright law. Copyright and IPR is retained by the creators or other copyright holders. Terms and conditions for use of this material are defined in the End User Agreement.

www.reading.ac.uk/centaur 
Central Archive at the University of Reading

Reading's research outputs online 


\section{The therapeutic role of video diaries: A qualitative study involving breastfeeding mothers}

\section{Abstract}

Background: Despite breastfeeding providing maximum health benefits to mother and baby, many women in the United Kingdom do not breastfeed, or do so briefly.

Purpose: Using tenets of ethnography, this study aimed to explore the everyday experiences of first time breastfeeding mothers in the early weeks following birth.

Methods: Using a camcorder, five mothers in the United Kingdom captured their real-time experiences in a video diary, until they perceived their infant feeding was established. Using a multidimensional approach to analysis, we examined how five mothers interacted with the camcorder as they shared their emotions, feelings, thoughts and actions in real-time.

Findings: Mothers recorded 294 video clips, total recording time exceeded 43 hours. This paper focuses on one theme, the therapeutic role of the camcorder in qualitative research. Four subthemes are discussed highlighting the therapeutic impact of talking to the camcorder: personifying the camcorder; using the camcorder as a confidante; a sounding board; and a mirror and motivator.

Conclusion. Frequent opportunities to relieve tension by talking to "someone" without interruption, judgement or advice can be therapeutic. Further research needs to explore how the video diary method can be integrated into standard postnatal care to provide benefits for a wider population.

Key words Psychology; Research as therapy; Video diaries; Breast Feeding; Counseling; Talking therapy 


\section{Statement of Significance}

\section{Problem}

Despite breastfeeding providing maximum health benefits to mother and baby, many women in the United Kingdom do not breastfeed, or do so only briefly

\section{What is Already Known}

Taking part in research can be therapeutic.

Within a culture of bottle feeding in the United Kingdom, breastfeeding mothers face many challenges including unrealistic expectations.

The diary method is a useful tool to collect qualitative data.

\section{What this Paper Adds}

- Video-diaries offer researchers real-time, audio-visual, everyday life data

- New mothers' need to talk about breastfeeding is greater than previously realised

- Keeping a camcorder research diary can be therapeutic

- Self-recording video-diaries is useful addition to the repertoire of research methods

\section{Introduction}

\subsection{Aim of this paper situated within the original study}

This paper will focus on one theme from the findings of a study in which mothers used small handheld camcorders to record their breastfeeding experiences on video diaries. It will highlight the way the mothers personified the camcorders which appeared to help them to express their emotions, fears and feelings. The analysis enabled new insights about the therapeutic role of taking part in qualitative research. 


\subsection{Background}

There is growing evidence of the potentially therapeutic nature of being a research participant. The 'therapeutic effect' is a 'meaning effect' in general, since it refers to the meaning of taking part in the research for participants.(1) People take part in research for different reasons such as wanting to help others and getting something more for themselves. Studies have consistently highlighted that qualitative research can have a therapeutic effect on participants.(2) This effect is also referred to as 'cathartic'.(3: p31)

\subsection{Study Context}

There is overwhelming research evidence that demonstrates the health and psychological benefits of breastfeeding for both mothers and babies and yet breastfeeding prevalence in the United Kingdom (UK) is one of the lowest in the world.(4) The most recent UK National Infant Feeding Survey (2010) revealed a culture of formula feeding: although $81 \%$ of mothers started breastfeeding, only $44 \%$ were exclusively breastfeeding one week later and $23 \%$ at six weeks.(5) Despite consistent evidence of its benefits, breastfeeding is often seen as problematic. The key social issues include unrealistic expectations, pressures from work, family, friends and partners, tensions caused by women's breasts being portrayed as sexual objects and marginalisation of women breastfeeding in public and widespread advertising of formula and bottle feeding.(6-9)

Studies have employed written and audio diaries to collect contemporaneous data providing evidence of mothers' on-going lived experiences of breastfeeding in the early weeks. $(10,11)$ Diaries are a useful method as the researcher cannot observe participants 24 hours a day, seven days a week. Instead of using retrospective data collection (interviews or surveys) which risks recall bias, diaries come as close as possible to continuous contemporaneous data collection. One study used daily diaries by mothers in the first six to eight weeks following birth, along with transcripts from interviews, to explore experiences of breastfeeding.(10) These researchers demonstrated how unprepared mothers were for breastfeeding despite expressing a strong preference to breastfeed 
antenatally, the difficulties they faced and the 'roller coaster' of emotions in the early weeks.(10, pe15) Leeming and colleagues (11) used a combination of audio diaries and semi-structured interviews to explore first-time mothers' experiences of breastfeeding following discharge from hospital. Their work highlighted social factors and difficulties of breastfeeding, including accessing support from health professionals.(11) However, audio-visual diary data has not been collected by breastfeeding mothers before. This study sought to fill this gap, enabling for the first time, the collection of audio-visual data of the multifaceted nature of breastfeeding at home from mothers' perspectives in the early weeks following birth to identify the challenges they face on a daily basis within their own socio-cultural context.

\section{Methods}

\subsection{Study design}

This qualitative study explored the everyday experiences of a small group of first-time mothers in the South of England, who were breastfeeding their babies in the early days following birth. This paper focuses on one theme, 'But what I really wanted to tell you...' - mothers' use of the camcorder.

Ethnography prioritises observation as the pivotal mode for gathering cultural information about a group of people.(12) Observing mothers' experiences of breastfeeding within their own homes, however, is impractical as it is intrusive to take up residence and become a 'participant observer' at such an important transitional period in new parents' lives. To gain a wide range of perspectives, mothers were asked to use a camcorder to record anything and everything they wished to share about their breastfeeding experiences, to enhance understandings and meanings related to the multifaceted and cultural nature of breastfeeding. Furthermore 'thick descriptions'(14: p86) together with quotations from the mothers' video diaries illustrated the interpretations and meanings of breastfeeding within its social context.

Five participants captured data on a camcorder in real-time as their infant feeding trajectory unfolded. The study aimed to gain new understandings about the challenges women face including 
the emotional, social and cultural aspects of living with a baby and the impact of these on breastfeeding. To gain an "emic perspective", the audio-visual recordings were used as a method to help understand mothers' perspectives, meanings and beliefs about their breastfeeding experience by seeing it "through their eyes".(14: p175) To gain an "etic perspective", observations in the mothers' own socio-cultural environment were interpreted.(14) This audio-visual method has been used before by health researchers but never with breastfeeding mothers. As Bates(15: p30) suggested in her research on people with long-term physical or mental health conditions, the purpose of the camcorder was to act as the "participant observer" constituting the researcher's "eyes and ears".

\subsection{Reflexivity}

Recognising that undertaking this study could be shaped by our culture, values, personal beliefs and experiences, we aimed for "empathetic neutrality"(16: p8), endeavouring to be neutral and nonjudgemental in our approach. This involved an increased awareness and reflexivity that the first author's experiences and values as an experienced midwife, midwifery lecturer, breastfeeding mother and advocate of breastfeeding might influence both mothers participating in the study and her own interpretations of their perspectives on breastfeeding. This was facilitated by the first author's fervour to hear mothers' unadulterated experiences of breastfeeding within their own social environments, where their opinions, values and feelings could be shared spontaneously as they occurred, and then listened to and respected with minimal influence from her. Thus, although her identity as a midwife was disclosed to participants, her keen interest in learning from and respecting mothers' experiences of breastfeeding was emphasised before they commenced data collection.

\subsection{Ethical Issues}

Informed written consent was obtained for creating the video diary at the pre-birth meeting and each time the video material was collected, as an "ongoing, renegotiable process".(17: p358). 
Mothers were not obliged to offer any video data that they deemed unsuitable for research purposes, therefore, prior to collection, they were requested to view and edit any unwanted material. None of the mothers chose to edit their video diaries and most had not re-played them before submission. Maintaining confidentially and anonymity was problematic, because data collection captured visual images. Because many people are familiar with reality TV programmes like 'Big Brother', they are also aware that providing personal space and a camcorder to record private thoughts and feelings can result in very revealing data. Using these examples helped participants understand the loss of confidentiality and anonymity if they were to take part in this study. The research was approved by the local NHS Research Ethics Committee.

Informed written consent was obtained for creating the video diary at the pre-birth meeting and each time the video material was collected, as an "ongoing, renegotiable process".(17: p358). Mothers were not obliged to offer any video data that they deemed unsuitable for research purposes, therefore, prior to collection, they were requested to view and edit any unwanted material. None of the mothers chose to edit their video diaries and most had not re-played them before submission.

\subsection{Pilot Study}

As this was a new method of data collection with breastfeeding mothers, a pilot study was conducted. The pilot participant (Vicky) was asked to keep a video diary for the first eight weeks of her baby's life or until her infant feeding method was established. She was requested to film anything that related to her breastfeeding experiences, including a daily monologue. The breadth and richness of her data informed and was subsequently included in the main study as she recorded much rich data: 121 video clips over five months.

\subsection{Participants and Recruitment}

Research employing video diaries on a daily basis for qualitative research used small numbers of participants (3-20), possibly because they collected a large volume of data. With varying numbers of 
participants which were not well rationalised in the literature, we proposed that approximately eight mothers would be recruited. The pilot study demonstrated the quantity as well as the quality, breadth and richness of data that could be recorded by just one person. Thus, after collecting 121 clips and more than 11 hours of data from the first mother, the number of proposed participants was reduced to five.

Following the pilot study, the first author met with community midwives from the local NHS Trust to discuss the study. These midwives distributed 'invitation packs' during routine scheduled antenatal appointments to English-speaking women (older than 16 years) expecting their first baby at 28-30 weeks pregnant. Each 'invitation pack' consisted of an invitation letter and information leaflet asking women to register their interest using the stamped addressed envelope. When only three responses were received in four months, the first author attended two parent-education classes where she spoke about the project and provided the midwife with further 'invitation packs' for attendees. A further four women made enquiries. On receipt of an expression of interest, the first author visited women at home to explain the study and to seek informed consent. All women who were visited at home consented. Participants and were provided with the camcorder for a short period in pregnancy to practise. They were visited again at home following the birth when the camcorder was provided to enable data collection to begin. At this point, it was ascertained that they still met the inclusion criteria of being in good general health and breastfeeding their first full-term healthy baby as well as the inclusion criteria previously described. Four out of the seven women who consented were recruited to the main study. Three mothers no longer fitted the inclusion criteria. Together with the pilot participant, five first-time mothers were included in the main study (Table 1). All described themselves as white British. Two were married and three cohabiting. Four participants had close family nearby.

\subsection{Data Collection}

Along with the camcorder and its instructions, each mother was provided 'guidelines for keeping the video diary' which were not intended to be prescriptive but to act as a springboard for conversation 
and filming and to reduce "procrastination" (18) Mothers were requested to maintain their video diaries until they perceived their method of infant feeding (breast and/or formula feeding) had become established, thus the data collection period was determined by the mother. Data, stored on memory cards together with informed consent for their future use, was collected from mothers' homes every 7 to 14 days. In total, participants recorded 294 video entries lasting 43 hours, 51 minutes and 38 seconds (Table 2).

\subsection{Data Analysis}

The first author viewed all video footage and the co-authors looked at selected clips to check the interpretation for quality control (12) ensuring the themes were not over-represented. (19) The authors were from a range of different disciplines including midwifery, sociology and social pharmacy. This enabled them to probe from different perspectives ensuring inter-subjectivity in the thematic analysis. (20) A multi-dimensional strategy, to analyse the audio and visual data together, included considering direction of mother's gaze (21), facial expressions (22), body language and how mothers angled the camera frame (23) alongside the spoken word. To prevent the potential loss of a layer of data through transcription (24) and embracing the opportunity of repeatedly viewing small segmented clips in an iterative process (25), "complete coding" was achieved across the entire data set using NVivo. This iterative process ensured our focus of analysis did not centre on the spoken word alone but facilitated our immersion into the cultural aspects of breastfeeding, assisting our ethnographic approach to analysis. The video diaries presented both objective data which was easily observed, and subjective data such as the emotional content that needed to be identified to interpret the psychological dimension of each diary entry (26). The iterative process enabled a multidimension approach to the analysis, because we were able to 'observe' the verbal content closely together with the visual, so that video clips could be "sliced" and coded multiple times and in multiple ways, through a simple drag and drop system within the NVivo software programme (27). Therefore, analysis and coding of emotions and behaviour derived from facial expressions (22) and 
body language (28), along with linguistic detail (29)was undertaken. "Slicing" the data and tagging the segments with codes enabled data to be collected together, compared and contrasted (27). We applied Braun and Clarke's (30) motto of "inclusivity", and worked through each video diary methodically, with our broad question in mind, informed by a social constructivist perspective. From this process, we derived 170 codes which were then examined for patterns of meaning, resulting in 27 categories, seven subthemes and three themes. Reliability was enhanced by good quality recording equipment.

This paper focuses on one theme, 'But what I really wanted to tell you...' - mothers' use of the camcorder. Four subthemes are discussed, illuminated by mothers' quotes providing an enhanced appreciation of their real-time experiences. Pseudonyms are used and the number after each name relates to the number of weeks following the birth.

\section{Findings}

Findings show that as mothers recorded their video diaries there was a therapeutic effect. This effect might have been greater than suggested in other qualitative research (18) because each participant had full control of the camcorder. Mothers recorded their video diaries for longer than expected. Perhaps breastfeeding took longer to establish than previous studies have proposed. However, the analysis suggested the more likely explanation to be that the video diaries provided an avenue for mothers to talk to someone. Subthemes included: 'Personifying the camcorder' and how it acted as a 'confidante', 'sounding board' and a 'potential mirror and motivator' whenever and wherever the participant chose.

\subsection{Personifying the camcorder}

Mothers personified the camcorder, having someone in mind as they shared their experiences of breastfeeding, personally addressing their video diary using greetings, "Hi 'name of first author'" 
(Rosie3), "I have an update for you today"' (Sam2), giving an impression that the principal audience was the first author. At other times, they chatted to themselves as they gazed at their mirror image in the camcorder screen. One mother was inconsistent in who she addressed. The flexibility to talk to whoever was on her mind at the time, enabled her to express her thoughts and feelings in a way that was meaningful to her, enabling her to vent her anger at people, especially health professionals, who had annoyed her. The person addressed sometimes changed between diary entries and even within the entry itself, as if at one moment she was complaining about someone to the researcher and the next making accusations directly to the person she was complaining about.

I think it shows how this lady was very nice but didn't meet any of my expectations at all [shaking head, pursing lips] You WERE crap, ok? Because you gave me a chart that apparently isn't right (Tracey6)

Thus, sometimes mothers' recordings were a set of private conversations with either the researcher or themselves, whilst at other times they were presented as something intended for a much wider audience.

\subsection{Confidante}

Mothers embodied the camcorder as a confidante and friend, or as an adversary to remonstrate with people. The time and commitment spent recording demonstrated the value they placed on expressing their inner thoughts and feelings about life with a breastfeeding baby to a trusted listener. The data highlighted the frequency, intensity, depth and lability of emotion that they experienced daily. Often clandestine in nature, these confessions included talking about changing family relationships and lifestyles and the huge shift from orderly routines to a chaotic disorderly existence that merged one day into another. Some of the intimate detail mothers divulged was highly confidential and for ethical reasons will not be shared, however, what this highlighted was the need for 'new' mothers to talk to someone at any time and in any place. 
I felt like you are my diary and someone I can talk to about what I was going through, and it was a cathartic release, that I could get problems off my chest and that once I had told you about my night it would feel a bit better and different things like that... (Vicky12)

The camcorder empowered them to pour out their hearts in real-time whenever they felt tension building up, with candid ways of expressing their thoughts and feelings. The absence of a real-time listener did not deter them. The spontaneity of recording demonstrated an impulsive act of sharing their experiences without any sense of planning or forethought. Mothers' apparel provided evidence of the timing, changing priorities and spontaneity of filming.

I'm completely exhausted, so much sleep deprivation when you breastfeed. It's not what it's all cracked up to be. I do understand and I can see how people give up... [Dressed in nightwear-18.40hrs] (Sam6)

Using the camcorder as a confidante enabled mothers to 'vent' and release some of their angst. Sometimes a sense of urgency to record was tangible. When these points of crisis occurred, frequency of filming often increased, which for one mother was up to five times in one day.

I'm losing my mind a little bit. And I don't know who you are or where you are watching me, but I'm grateful for allowing me to vent, because I think if all this was penting up inside of me, I think I would have exploded a long time ago...(Tracey12)

For some, the camcorder helped alleviate their isolation, 'trapped' in their own home. The camcorder replaced the adult company they craved.

If I'm at home by myself ...it's exhausting ...I can't hand her over, you know, just for the 10 minutes that it takes to fold the laundry or [shaking head] go to the toilet even ...it's really limited what I can do and I'm really tied to her. (Rosie5)

Mothers provided visual data which, when analysed alongside the verbal data, revealed compelling evidence of the depth and range of emotions in a very short space of time. Their emotions 'yo-yoed' 
back and forth with positive emotions demonstrated when mothers felt proud of themselves because breastfeeding was going well, and negative emotions brought on by doubt as to whether breastfeeding was working and whether it was even possible to continue. The range of emotions varied from day to day, and sometimes they changed within the video clip itself in an "emotional rollercoaster".(10: p15)

Experiencing breastfeeding problems in addition to the frequency and intensity of breastfeeding and exhaustion, sent mothers spiralling downwards emotionally. Using the camcorder as a confidante enabled four out of five participants to share their deep emotional pain and feelings of failure and guilt.

Everything that I felt I worked for...went down the drain this morning when I gave her formula [starting to cry]...so my experience of breastfeeding... has been pretty miserable [crying] because I'm not breastfeeding anymore...and I'm having to use this breast pump...sorry for getting upset...just feel like I've failed but I'm going to get back to it. (Sarah2)

Despite feeling inadequate and deeply frustrated because of tiredness and an inability to keep up daily routines, mothers still prioritised recording their diaries. Confiding in the camcorder took precedence over other needs, perhaps they felt a sense of responsibility for the research or perhaps it was more about the cathartic release.

\subsection{Sounding Board}

Mothers also used the camcorder as a 'sounding board', to 'think out loud', rationalise what was happening to them and work out strategies to cope with the unexpected challenges including relentless breastfeeding. Using the camcorder in this way helped some mothers to feel more confident and less stressed encouraging a more relaxed approach to breastfeeding. At four weeks, after experiencing a spate of unsettled evenings and wrestling with her inner thoughts and feelings about breastfeeding on camcorder, Vicky finally worked it out for herself. 
... he's either doing cluster feeding or maybe that's just how it goes, he just stocks up in the evening. So I think I need to be more relaxed and less of, oh nooooo, and try and settle him down... in the evenings I sit and feed, that's what I do. (Vicky4)

The relentless feeding left some mothers feeling vulnerable, as if they were fighting a never-ending battle. Not understanding the reason for this, mothers used the camcorder to share desperate measures that they knew were contrary to the advice they had been given but perhaps required some acknowledgement.

...a very small amount [of cow's milk cream], when the baby was crying managed to go onto his dummy, and seemed to work [nodding] very well, and that happened twice because I was desperate for five minutes of peace and quiet, so I know he was only seven weeks old and you are not really supposed to do that but, it was fresh. (Tracey9)

Using the camcorder to work out night-time strategies frequently occurred and bedsharing was a recurring topic of conversation. For some the feeling of exhaustion and desperation overtook rational thinking at the time. It was only when they used the camcorder to reflect on this contentious issue, that they realised the tension between what they did and what they believed to be safe. For others rationalising their actions on camcorder confirmed that the benefits from gaining sleep far outweighed the risks.

I was always led to believe that you don't put a child into bed with you. If you were to roll over you could squash them and they could die?... I wouldn't want to suffocate my own child obviously... but that's what they [peer support group] suggested and last night that did work for us. So didn't think it was a very good idea. Won't be doing that again! We were just so exhausted. (Sam4) 
... and if she kind of finishes one side ...just turn myself a bit more, so that she can get the other breast and I was thinking, what is that like for her? Is it...this kind of amazing feeling of sort of being in heaven and milk comes raining down on you? [laughing] (Rosie3)

All five mothers endured sore or bleeding nipples requiring them to work out the cause and how to make them better. Demonstrating on camera exactly how they were attaching and feeding enabled some to question and validate what they were doing: "I'm doing this so you can see the swallow suck" (Vicky11). Using the camcorder as a sounding board provided an opportunity to think out loud, focusing on their baby's attachment from a different angle, the camcorder's viewpoint, helping them to reflect upon what they might do differently to make breastfeeding more comfortable.

\subsection{Mirror and Motivator}

Having natural conversations with themselves meant that the camcorder became a tool for personal reflection about their physical, emotional and psychological wellbeing. For example,

I'm just looking at the picture of like me filming this and this just isn't me, this isn't who I am, I'm not somebody that's like angry all the time (Tracey12)

Reflecting on their lives before and after childbirth resulted in an enhanced understanding of how chaotic life had become and a renewed motivation to keep going. Striving for balance between the 'work' of continuous feeding, 'rest' enabling sleep and recuperation, and 'play' to do other things, meant they set goals and developed strategies to accomplish as much as possible. When they achieved more than breastfeeding, they felt successful, when they only managed breastfeeding, they felt down-hearted.

I don't manage to do anything and just spend my whole life trying to sleep and doing breastfeeding and flopping about ...I'm just still quite tired and I've got into a mode where the days just drift along and I don't know what time it is. (Rosie2) 
The moral obligation to continue breastfeeding despite adversity felt palpable at times as they explained why breastfeeding was important. Each mothers' diary entries were a testimony to her motivation, determination and endurance. Sarah, in particular was unwilling to accept her changed identity as a 'formula feeding' mother having given a bottle when 'resting' cracked nipples. Setting numerous goals during diary recordings, she demonstrated resilience and determination sometimes regressing and progressing before regaining what she perceived to be her identity as a breastfeeding mother during the thirteenth week.

I've come to a decision [pause] and I've completely got rid of all bottles [laughing], all formula has gone, Sophie is now completely breastfed... I've completely ditched the formula because I'm stubborn and I wanted a breastfed baby and now I've got one, it only took three months (Sarah13)

\section{Discussion}

\subsection{Strengths and Limitations}

This study used data from video diaries of five mothers in the South of England. The data may not be generalisable to other mothers and babies within the global context but the findings have been corroborated by and added depth to many international studies that have previously used many different qualitative research methods. The authors brought a range of perspectives but researchers from different disciplines might have offered different interpretations of the data. Additionally, our findings when presented at international and local conferences have resonated with many delegates.

Filming themselves enabled mothers to decide how they portrayed themselves which might have been influenced by the first author's transparency about being a midwife. However, asking the mothers to film their own experiences engendered a closeness between the first author and participants, because they knew that she would watch and listen intently to the videos even though she was at a distance from them physically. Thus, the presence as a midwifery researcher was not 
overwhelming or detrimental to data collection. Providing guidance might also have influenced their decisions and resulted in the data being co-created with the mothers, but as mothers relaxed into recording, they disclosed personal issues in their everyday interactions with a breastfeeding baby that were unanticipated. Thus, rather than a weakness, capturing the spontaneity of experience was a strength, as mothers shared what was important to them, often capturing action as it was happening which offered fresh insights into what was troubling them and how they dealt with it.

\subsection{Discussion within the context of the literature}

The qualitative research process can have a therapeutic effect on participants, particularly when sequential interviews are involved.(2) Ortiz(2: p99), found a therapeutic effect when he interviewed 48 wives of professional athletes because they were provided with the opportunity "to cathartically release unpleasant or pent up feelings" in their everyday lives. Finding himself an "accidental therapist", $\operatorname{Ortiz}(2: \mathrm{p} 196)$ suggested that the longitudinal nature of the study helped to develop an attentive, trusting, non-judgemental relationship with participants, encouraging emotional selfrevelations to be expressed with subsequent stress relief. Dickson-Swift and colleagues (31) argued that although the qualitative interviewer and psychotherapist are comparable, the former potentially has more time for active listening and gentle probing. In our study, mothers used the camcorder as the eyes and ears of the active listener to share feelings and experiences, and, like other research involving video diaries, often addressed the researcher personally.(15) Perhaps, the neutral nature of the camcorder being "something to talk to that would never answer back"(27: p10) meant that mothers were able to share candid accounts and to agonise over how they were feeling and what they were thinking, without fear of retribution or judgement. This may have prevented a build-up of emotions that might otherwise have been difficult to manage.

The clandestine feel of video diaries has been reported before. Holliday(33) found that participants revealed more intimate details when alone than in the company of others. Renov(34) argued that emotional outpouring can be encouraged more effectively using a virtual companion than a face-to- 
face conversation with a real person. We also found mothers positively buoyant in recorded conversation with family and friends but displaying unguarded emotional turbulence when alone with the camcorder. This suggests the need for mothers to confide in someone other than family and friends.

Scheff(30: p45) described catharsis as "the process of emotional discharge which brings relief to emotional tension." Conversely, suppressing thoughts and feelings can cause short-term physiological changes in the body, long-term morbidity and reduces clarity of thought.(35) In this study, when mothers faced unexpected challenges, they expressed their anxieties, feelings and emotions in realtime including immediate reactions and spontaneous emotions. Most mothers cried on camera, and then often apologised and expressed relief afterwards. This apology might have indicated a learned response that crying should be limited(35) and yet the recordings showed mothers thinking more clearly following emotional release, and expressing renewed determination to continue breastfeeding.

An effective therapy for mothers with mild to moderate postnatal depression (PND) is non-directive counselling by health visitors via 'listening visits'.(36) Turner and colleagues(32: p236) reported that participants found 'offloading' suppressed feelings to an unknown researcher particularly helpful because they had not previously disclosed these to anyone. The word 'offload' was also used by our participants in relation to an outpouring of feelings to 'someone' they perceived as nonjudgemental. The mothers in our study had not been diagnosed with PND, but still needed to talk to 'someone', expressing similar concerns including expectations as new mothers, feelings towards their baby, changing relationships with their partner and financial difficulties. The non-directive counselling approach also encourages women to rationalise their feelings including working out coping strategies.(36) In our study, mothers did not wait to see a health professional; instead by talking to the camcorder they spontaneously rationalised their own feelings and developed their own coping strategies. 
Brett(38) argued that diarists often omit writing about emotional turmoil for fear of it causing more angst. Here, some mothers also omitted to record for a few days when life became more chaotic than usual, while others recorded more. However, not being limited to scheduled visits for 'offloading' meant that they also turned on the camcorder at any time, one doing so eight times in one 24-hour period. In contrast, mothers in our study continued recording their diaries until they felt their infant feeding method was established, which took longer than the research proposal had envisaged. Arguably the therapeutic benefits they were experiencing meant they needed to 'wean' themselves gradually from the camcorder and they did not stop until they were ready. Despite the small number of participants, the length of time for which the mothers breastfed, compared to national statistics(5), was noteworthy. Four out of the five mothers were exclusively breastfeeding at six weeks with one breastfeeding alongside formula feeding, thus all were doing some breastfeeding. A Hawthorne effect might have been the reason for the mothers to have continued breastfeeding but it could also be argued that they were already motivated to breastfeed for a lengthy period and that is why they consented to the research.

Two mothers in particular, 'let off steam' with impulsive bouts of anger, venting their complaints at a person or group with whom they were upset. Renov (29: p88) proposed that interaction with the video camcorder, especially of a confessional nature, could also be with an "absent imaginary other". Using a reflexive approach, we realised that the mother was replacing the researcher as the imagined listener with people who had caused irritation and anger. Ortiz(2: p206) experienced similar angry responses during interviews, feeling under attack like a "substitute husband". He noticed, however, that self-disclosure accompanied by angry discharge assisted rationalised thinking, self-revelations and problem solving. Catharsis, thus fits with Breuer and Freud's theory (39), that openly expressing personal anger rather than holding feelings in, prevents long-term resentment and hostility. The therapeutic effect of offloading via the camcorder resulted in one mother believing that she was gaining emotional comfort from talking to it. 
These findings, however, need to be treated with caution, because a perceived catharsis does not necessarily mean an actual recovery. Exploring whether talking about an emotional episode aids recovery, Zech and Rimé(40) found that participants who talked about their emotions were less likely to recover than those who kept to factual descriptions of the event. Thus a "repetitive uncontrolled process through sharing or thinking" can impede recovery, whereas a "more constructive, insightful and controlled process" leads to more positive outcomes.(35: p285) One mother's diary entries were often turbulent with feelings of anger expressed repetitively about the lack of support from the health professional who called her baby 'scrawny'. Self-regulation of emotions is linked with emotional processing. Wilkins et al.(36: p155), exploring the latter in childbirth, suggested that when someone is having difficulty regulating their emotions they may show "repeated or intrusive memories of a stressful event, a reliving of the original emotions". For one mother, the repetitive discussion reinforced the word 'scrawny', appearing to make her angrier every time she spoke about it.

Mutual gaze, when people are looking at each other, is an important part of communication as it helps to regulate and manage a conversation. Notably, participants mostly talked to their diaries alone and therefore did not need to constrain their conversation with another person, and yet they still made eye contact with their own image in the camcorder. Adams and Kleck(42) suggested that eye contact is averted when people experience fear and sadness, whereas it is protracted with anger and joy. In this study, the mutual gaze of participants was also linked with similar emotional states. When mothers were feeling sad and tearful, when breastfeeding was not going well, mutual gaze with themselves was avoided but when they were angry or joyful they looked directly at themselves in the camcorder screen.

Mothers defined their identity when they saw their mirror image on screen, in a way that research exploring women's experiences of breastfeeding has not reported before. For some, this appeared to trigger a deeper reflection resulting in an identity crisis because they were shocked by the change. 
While this method of reflecting has not been highlighted in research exploring breastfeeding before, Holliday(28: p53) suggested that the mirror image, facilitated through the camcorder monitor provided a 'narcissistic' function enabling the participant to speak candidly to themselves as an imagined viewer. Thus, the diaries offered a safe place to talk out loud to themselves as they tried to work out how to survive as breastfeeding mothers. People use self-reflection to purposefully consider experiences that have impacted on them by evaluating their thoughts, feelings and actions to better understand what occurred.(43) Educational theory suggests that reflection is triggered particularly when a dissonance occurs between people's experience and their expectations or beliefs, creating the potential for transformation.(44) In this study, the unexpected realities of breastfeeding caused a dissonance which mothers needed to work through, triggering reflective discourse within the video diaries. Research using video diaries found that enhanced self-awareness occurred when participants spent recording time working out their experiences.(33) Brown and colleagues(24: p428), suggested that this self-awareness brings about a "cognizance" with potential for transformation. Like Kindon's (45) research using video diaries with Maori women in New Zealand, mothers in our study appeared to use their own reflections to analyse their experiences of breastfeeding. This provided "holistic transformative potential"(40; p148) empowering them to work out for themselves how to negotiate breastfeeding within the context of their daily lives providing a renewed determination to continue breastfeeding.

Personifying the camcorder enabled a unique presence of being there as an invited guest to observe and to hear about some of the most embodied, intimate, emotional, both joyful and troubled moments in their early weeks of motherhood. This provided valuable insights about how mothers used the camcorder to offload within their own socio-cultural environment.

\section{Conclusion}

This study shows that new mothers need frequent opportunities to relieve tension by talking to someone about their thoughts, feelings and experience of breastfeeding without interruption, 
judgement or advice from another. Findings identified a therapeutic effect from recording because the camcorder became a confidante for emotional outpouring which brought about a cathartic release. As mothers attempted to come to terms with the unexpected challenges of breastfeeding, they used the camcorder as a sounding board by working out how they could cope. Using the mirror image on the camcorder screen instigated natural conversations with themselves resulting in personal reflection, self-awareness, resilience and a renewed determination to breastfeed. With low breastfeeding rates in the UK, and reduced postnatal services to support breastfeeding (46), we need to explore alternative interventions that will enhance mother's experiences of breastfeeding. The therapeutic effect of using video diaries needs to be considered alongside other methods that would encourage mothers to talk. Further research could include the development and evaluation of an internet breastfeeding support service, based on telehealth, offered in 'real-time', fostering principles of a 'listening service' provided by the health service and supported by trained members of the healthcare team or trained breastfeeding counsellors and/or peer supporters. Further research should explore the therapeutic effect of online social networking groups, specifically for breastfeeding support, where opportunities for 'offloading' are available 24 hours a day but where participants could be subject to unwanted judgmental advice.

To conclude, a therapeutic effect could be achieved by using video diaries. Further research needs to explore how this method could be used more widely to enhance health outcomes for a wider population.

\section{Acknowledgements}

We wish to thank (to be added...)

\section{References}

Walach H, Sadaghiani C, Dehm C, Bierman D. The therapeutic effect of clinical trials: understanding placebo response rates in clinical trials - A secondary analysis. BMC Med Res Methodol. 2005;5(26):1-12. 
2. Ortiz SM. How Interviewing Became Therapy for Wives of Professional Athletes: Learning From a Serendipitous Experience. Qual Inq. 2001;7(2):192-220.

3. Spencer R, Hinsliff-Smith K, Walsh D. An exploration of infant feeding experiences of women in Lincolnshire in the early postnatal period: Report of a Project Commissioned by NHS Lincolnshire. [Internet]. Nottingham; 2012. Available from: https://www.nottingham.ac.uk/research/groups/mcph/documents/mchp-project-reportinfant-feeding.pdf

4. Victora CG, Bahl R, Barros AJD, França GVA, Horton S, Krasevec J, et al. Breastfeeding in the 21st century: epidemiology, mechanisms, and lifelong effect. Lancet. 2016;387(10017):47590.

5. McAndrew F, Thompson J, Fellows L, Large A, Speed M, Renfrew MJ. Infant Feeding Survey 2010 [Internet]. [online] Dundee: The Information Centre for Health and Social Care. Available from: http://data.gov.uk/dataset/infant-feeding-survey-2010 [Accessed 2 June 2015].; 2012 [cited 2015 Jun 3]. Available from: http://data.gov.uk/dataset/infant-feedingsurvey-2010 [Accessed 2 June 2015]

6. Hoddinott P, Craig L, Britten J, M Mclnnes R. A serial qualitative interview study of infant feeding experiences: idealism meets realism. BMJ Open [Internet]. 2012;2(e000504):1-17. Available from: http://bmjopen.bmj.com/content/2/2/e000504.full.pdf+html

7. Lavender T, McFadden C, Baker L. Breastfeeding and family life. Matern Child Nutr. 2006;2(3):145-55.

8. Dykes F. Resisting the gaze: the subversive nature of breastfeeding. In: Kirkham M, editor. Exploring the Dirty Side of Women's Health. Abingdon: Routledge; 2007. p. 87-100.

9. Brady JP. Marketing breast milk substitutes : problems and perils throughout the world. Arch Desease Chidhood. 2012;97(6):529-32.

10. Hinsliff-Smith K, Spencer R, Walsh D. Realities, difficulties, and outcomes for mothers choosing to breastfeed: primigravid mothers experiences in the early postpartum period (6-8 weeks). Midwifery [Internet]. 2014 Jan [cited 2014 Nov 14];30(1):e14-9. Available from: http://www.ncbi.nlm.nih.gov/pubmed/24238980

11. Leeming D, Williamson I, Johnson S, Lyttle S. Making use of expertise: A qualitative analysis of the experience of breastfeeding support for first-time mothers. Matern Child Nutr. 2015;11(4):687-702.

12. Creswell JW. Qualitative Inquiry and Research Design: Choosing Among Five Approaches. 3rd ed. Los Angeles: Sage; 2013.

13. Denscombe M. The Good Research Guide. 5th ed. Maidenhead: Open University Press; 2014.

14. Donovan P. Ethnography. In: Cluett E, Bluff R, editors. Principles and Practice of Research in Midwifery. 2nd ed. Edinburgh: Churchill Livingstone Elsevier; 2006. p. 172-86.

15. Bates C. Video diaries: audio-visual research methods and the elusive body. Vis Stud 
[Internet]. 2013;28(1):29-37. Available from:

http://www.tandfonline.com.libezproxy.bournemouth.ac.uk/doi/pdf/10.1080/1472586X.201 3.765203 ?noFrame=true

16. Ormston R, Spencer L, Barnard M, Snape D. The Foundations of Qualitative Research. In: Ritchie J, Lewis J, Nicholls CM, Ormston R, editors. Qualitative Research Practice: A Guide for Social Science Students and Researchers. 2nd ed. London: Sage; 2014. p. 2-25.

17. Dockett S, Perry B, Kearney E, Hampshire A, Mason J, Schmied V. Researching with families: Ethical issues and situations. Contemp Issues Early Child. 2009;10(4):353-65.

18. Brown C, Costley C, Friend L, Varey R. Capturing their dream: Video diaries and minority consumers. Consum Mark Cult. 2010;13(4):419-36.

19. Holloway I, Wheeler S. Qualitative Research in Nursing. Oxford: Blackwell Science; 2002.

20. Braun V, Clarke V. Using thematic analysis in psychology. Qual Res Psychol [Internet]. 2006;3(2):77-101. Available from: http://eprints.uwe.ac.uk/11735/1/thematic_analysis_revised_-_final.doc

21. Goodwin C. Practices of seeing: Visual analysis: An ethnomethodological approach. In: Van L, Carey J, editors. Handbook of Visual Analysis. London: Sage Publications; 2000. p. 157-82.

22. Peräkylä A, Ruusuvuori JK. Facial expression in assessment. In: Knoblauch H, Schnettler B, Raab J, Soeffner H-G, editors. Video Analysis: Methodology and Methods. Frankfurt am Main: Peter Lang; 2009. p. 127-42.

23. Mondada L. Video recording as the reflexive preservation and configuration of phenomenal features for analysis. In: Knoblauch H, Raab J, Soeffner H-G, Schnettler B, editors. Video Analysis: Methodology and Methods. Frankfurt am Main: Peter Lang; 2009. p. 51-67.

24. Markle D, West R, Rich P. Beyond Transcription: Technology, Change, and Refinement of Method. Forum Qual Soc Res [Internet]. 2011 [cited 2015 May 19];12(3):Art 21. Available from: http://www.qualitative-research.net/index.php/fqs/article/view/1564/3249

25. Cotton DR, Stokes A, Cotton PA. Using Observational Methods to Research the Student Experience. J Geogr High Educ. 2010;34(3):463-73.

26. Rich M, Patashnick J. Narrative research with audiovisual data: Video Intervention/Prevention Assessment (VIA) and NVivo. Int J Soc Res Methodol. 2002;5(3):245-61.

27. Bazely P, Jackson K. Qualitative Data Analysis with Nvivo. 2nd ed. London: Sage Publications Ltd; 2013.

28. Argyle M. Bodily Communication. 2nd ed. London: Routledge; 1990.

29. Svensson MS, Luff $P$, Heath $C$. Embedding instruction in practice: Contingency and collaboration during surgical training. Sociol Health IIIn. 2009;31(6):889-906.

30. Braun V, Clarke V. Successful Qualitative Research: a practical guide for beginners. London: Sage Publications Ltd; 2013. 
31. Dickson-Swift V, James EL, Kippen S, Liamputtong P. Blurring boundaries in qualitative health research on sensitive topics. Qual Health Res. 2006;16(6):853-71.

32. Dowmunt T. Dear Diary: Video Diaries, Subjectivity and Media Power. International Communication Association Pre-Conference: "Our Media Not Theirs." The American University, 21 May 2001; 2001.

33. Holliday R. Reflecting the Self. In: Knowles C, Sweetman P, editors. Picturing the Social Landscape: Visual Methods and the Sociological Imagination. London: Routledge; 2004. p. 49-64.

34. Renov M. Video Confessions. In: Renov M, Suderburg E, editors. Resolutions: Contemporary Video Practices. 1st ed. Minneapolis: University of Minnesota Press; 1996. p. 78-101.

35. Scheff TJ. Cartharsis in Healing, Ritual, and Drama. Lincoln US: iUniverse.com, Inc; 2001.

36. Hanley J. Listening Visits in Perinatal Mental Health. London: Routledge; 2015.

37. Turner KM, Chew-Graham C, Folkes L, Sharp D. Women's experiences of health visitor delivered listening visits as a treatment for postnatal depression: A qualitative study. Patient Educ Couns. 2010;78(2):234-9.

38. Brett S. The Faber Book of Diaries. London: Faber and Faber; 1987. vii-xii.

39. Breuer J, Freud S. Studies in Hysteria. Harmondsworth: Penguin; 1974.

40. Zech E, Rimé B. Is talking about an emotional experience helpful? Effects on emotional recovery and perceived benefits. Clin Psychol Psychother. 2005;12(4):270-87.

41. Wilkins C, Baker R, Bick D, Thomas P. Emotional processing in childbirth: A predictor of postnatal depression? Br J Midwifery [Internet]. 2009;17(3):154-9. Available from: http://eprints.bournemouth.ac.uk/15007/1/licence.txt

42. Adams RB, Kleck RE. Perceived Gaze Direction and the Processing of Facial Displays of Emotion. Psychol Sci. 2003;14(6):644-7.

43. Wood J. Transformation through Journal Writing: The Art of Self Reflection for the Helping Professions. London: Jessica Kingsley Publishers; 2013.

44. Jarvis P. Transforming learners through open and distant education. In: Jarvis $P$, editor. The Theory and Practice of Teaching. Abingdon: Routledge; 2006. p. 224-36.

45. Kindon S. Participatory video in geographic research: a feminist practice of looking? Area. 2003;35(2):142-53.

46. The Royal College of Midwives. Pressure Points. Postnatal care funding The case for better resourced maternity care. London; 2014. 


\begin{tabular}{|c|c|c|c|c|c|c|}
\hline 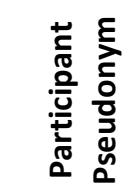 & 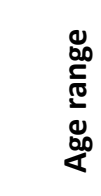 & 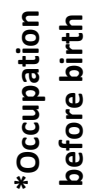 & 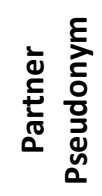 & 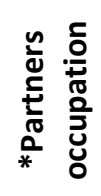 & 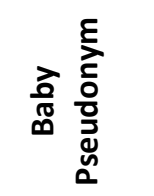 & 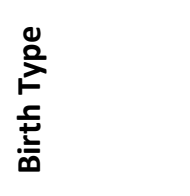 \\
\hline Rosie & $25-29$ & 5 & Tom & 6 & Lily & Home birth \\
\hline Sam & $20-24$ & 10 & Ralph & 8 & Zac & Normal \\
\hline Sarah & $25-29$ & 2 & Jason & 5 & Sophie & Normal \\
\hline Tracey & $20-24$ & $6+7$ & Scott & 2 & Theo & Forceps \\
\hline Vicky & $25-29$ & 2 & Peter & 3 & Benjamin & Normal \\
\hline
\end{tabular}

\section{*Office for National Statistics: Standard Occupational Classification Hierarchy with Group 10 added}

Group 1: Managers, directors and senior officials

Group 2: Professional Occupation

Group 3: Associate professional and technical occupations

Group 4: Administrative and secretarial occupations

Group 5: Skilled trades occupations
Group 6: Caring, Leisure and other service occupations

Group 7: Sales and customer service occupations

Group 8: Process, plant and machine operators

Group 9: Elementary occupations

Group 10: Unemployed, students, voluntary work

Table 1: Participants' Profiles 
Table 2: Video diary recording details for each mother

\begin{tabular}{|c|c|c|c|c|c|c|c|}
\hline $\begin{array}{l}\text { Participant } \\
\text { Pseudonym }\end{array}$ & $\begin{array}{l}\text { Average } \\
\text { length of a } \\
\text { recording }\end{array}$ & $\begin{array}{l}\text { Number of } \\
\text { days/weeks } \\
\text { recorded } \\
\text { over }\end{array}$ & $\begin{array}{l}\text { Max } \\
\text { number of } \\
\text { recordings } \\
\text { in any one } \\
\text { day }\end{array}$ & $\begin{array}{l}\text { Shortest } \\
\text { recording }\end{array}$ & $\begin{array}{l}\text { Longest } \\
\text { recording }\end{array}$ & $\begin{array}{l}\text { Total time } \\
\text { recording }\end{array}$ & $\begin{array}{l}\text { Total } \\
\text { number of } \\
\text { recordings }\end{array}$ \\
\hline Rosie & 18 minutes & $\begin{array}{l}63 \text { days } \\
9 \text { weeks }\end{array}$ & 3 & 9 seconds & $\begin{array}{l}43 \text { minutes } \\
20 \text { seconds }\end{array}$ & $\begin{array}{l}14 \text { hours } \\
59 \text { minutes } \\
35 \text { seconds }\end{array}$ & 51 \\
\hline Sam & $\begin{array}{l}4 \text { minutes } \\
48 \text { seconds }\end{array}$ & $\begin{array}{l}48 \text { days } \\
6^{+5} \text { weeks }\end{array}$ & 2 & $\begin{array}{l}1 \text { minute } \\
49 \text { seconds }\end{array}$ & $\begin{array}{l}20 \text { minutes } \\
38 \text { seconds }\end{array}$ & $\begin{array}{c}1 \text { hour } \\
26 \text { minutes } \\
32 \text { seconds }\end{array}$ & 18 \\
\hline Sarah & $\begin{array}{l}8 \text { minutes } \\
22 \text { seconds }\end{array}$ & $\begin{array}{c}87 \text { days } \\
12^{+3} \text { weeks }\end{array}$ & 2 & $\begin{array}{l}1 \text { minute } \\
10 \text { seconds }\end{array}$ & $\begin{array}{l}32 \text { minutes } \\
48 \text { seconds }\end{array}$ & $\begin{array}{l}4 \text { hours } \\
19 \text { minutes } \\
36 \text { seconds }\end{array}$ & 33 \\
\hline Tracey & $\begin{array}{l}12 \text { minutes } \\
33 \text { seconds }\end{array}$ & $\begin{array}{l}130 \text { days } \\
18^{+4} \text { weeks }\end{array}$ & 6 & 27 seconds & $\begin{array}{l}57 \text { minutes } \\
42 \text { seconds }\end{array}$ & $\begin{array}{l}11 \text { hours } \\
42 \text { minutes } \\
52 \text { seconds }\end{array}$ & 71 \\
\hline Vicky & $\begin{array}{l}8 \text { minutes } \\
9 \text { seconds }\end{array}$ & $\begin{array}{l}123 \text { days } \\
17^{+4} \text { weeks }\end{array}$ & 8 & 17 seconds & $\begin{array}{c}1 \text { hour } \\
12 \text { minutes } \\
45 \text { seconds }\end{array}$ & $\begin{array}{l}11 \text { hours } \\
23 \text { minutes } \\
3 \text { seconds }\end{array}$ & 121 \\
\hline
\end{tabular}

